\title{
Separation Efficiency of Oil and Water from Oilfield Produced Water Using Cyclonic Flotation
}

\author{
Jianfei Liu ${ }^{1,2, *}$, Hongbing Zhao ${ }^{1}$, Huifang $\mathrm{Li}^{1}$, Weilong Zhao ${ }^{1}$, and Yongsheng Zhang ${ }^{1,2}$ \\ ${ }^{1}$ School of Civil Engineering, Henan Polytechnic University, Jiaozuo 454003, China \\ ${ }^{2}$ International Joint Research Laboratory of Henan Province for Underground Space Development and Disaster Prevention, Henan \\ Polytechnic University, Jiaozuo 454003, China
}

Received 12 September 2020; Accepted 5 December 2020

\begin{abstract}
To improve the separation efficiency of oil field-produced water, a novel oil-water separation apparatus is developed. The high-efficiency cyclone separation apparatus could meet the continued increase of oil field-produced water and comply with the improvements in emission standards. Effectivity of the self-designed apparatus in oil removal was determined in laboratory and field tests. The effects of inlet flow, oil concentration and aeration amount were determined through laboratory tests. The particle size distribution of the influent and effluent oil-produced water was presented also. Results show that under optimal process conditions, i.e., the inlet flow rate is $2.0 \mathrm{~m}^{3} / \mathrm{h}$, imported oil concentration is $1189 \mathrm{mg} / \mathrm{L}$, and aeration rate is $0.6 \mathrm{~L} / \mathrm{min}$, effective separation can reach $93.1 \%$. The oil removal rate is generally above $90 \%$ and the range of influent concentration is $900-1200 \mathrm{mg} / \mathrm{L}$ in the field test. Compared to the traditional oilfield produced water treatment device, the self-designed apparatus can combine both air flotation separation and cyclonic separation. The joint effect of the two kinds of separation, can promote the collision adsorption probability of micro bubbles and oil droplets, and effectively improve the separation efficient.
\end{abstract}

Keywords: Separation efficiency, Oilfield produced water, Cyclone air flotation, Apparatus

\section{Introduction}

Petroleum is the main energy source of social development worldwide. Huge amounts of oil field-produced water containing oil are produced in the process of oil and natural gas production every day. Oil field-produced water contains many organic matters, such as phenols, benzene series, petroleum hydrocarbons, and polycyclic aromatic hydrocarbons, which are considered harmful to human beings and the ecological environment [1-2]. The produced water effluent from the separator treatment of petroleum industries is usually disposed of injection underground into permitted geologic horizons. Reinjection water must meet the local effluent limits to avoid of polluting the soil and groundwater as well as polluting the surface water through seepage.

Various separation techniques for oilfield produced water have been proposed based on different principles. The most commonly used techniques include coagulation, flocculation, flotation, adsorption, centrifuge, membrane filtration, ion-exchange, and biological or electrolytic methods. These treatment technologies have been summarized and their characteristics compared in several studies [3-5]. To achieve high efficient separation using air flotation, coagulation and flocculation is often required to form the bubble-floc aggregates. However, with the addition of coagulants means adding another chemical to the oilfield produced water, which increases the cost of treatment.

Therefore, the development of a simple and efficient oil-

*E-mail address: jzitlif@foxmail.com

ISSN: 1791-2377 @ 2020 School of Science, IHU. All rights reserved. doi:10.25103/jestr.136.09 containing wastewater treatment process has attracted much attention in recent years. A process of separating oil and water has been designed based on the air flotation without the addition of chemical. It is of great significance to study the oil-water separation mechanism and influencing factors by the combined the cyclonic and flotation separation.

\section{State of the art}

The gas flotation process, as an environmentally friendly treatment method for no moving parts, higher efficiency due to coalescence, easy operation, robust and durable characteristics, has been applied widely in recent years [6-8]. Literature on gas flotation was summarized in 2016 by Saththasivam et al. [9]. Some updated studies have also been conducted. The integration of micro and macro bubbles in a flotation system was proposed to enhance oil removal efficiency and results demonstrated a significant increase in oil removal to up to $68.6 \%$ under oil-wet conditions while almost all oil contaminants was removed [10]. Huang et al. designed a new type of high-efficiency counter-flow hydro cyclones, which were studied through numerical simulation and experiment [11]. Etchepare et al. investigated the separation of emulsified crude oil in saline water with micro bubbles and nano bubbles and the results showed the oil removal efficiencies of up to $90 \%$ with isolated nanobubbles [12]. Wang et al. develop a vortex floating technology on the floating production storage and offloading vessel of the offshore oilfield in the Western South China Sea [13]. Yan et al. studied the attachment processes between gas bubbles and oil droplets with different bubble sizes and different oil properties both experimentally and theoretically by a high-speed camera [14]. All the above 


\section{Jianfei Liu, Hongbing Zhao, Huifang Li, Weilong Zhao, and Yongsheng Zhang/}

Journal of Engineering Science and Technology Review 13 (6) (2020) 61 - 67

literature shows the feasibility of treating oilfield produced water by air flotation.

Since oilfield produced water often has the characteristics of complicated components, there is a tendency to assist other methods on the basis of air flotation. In the work of Ammar \& Akbar, a conventional internalloop airlift reactor was utilized as electrocoagulation flotation cell for produced water treatment by inserting two aluminum electrodes in the riser section of the airlift reactor. The experimental results showed that the oil removal efficiency could reach at $90 \%$ in 15 min [15]. Gebreyohannes et al. analyzed the recent developments made in the treatment of olive mill wastewater [16]. Liu et al. studied the cyclonic separation function mechanism of the cyclonic-static micro bubble flotation column and investigated the impact of the parameters including the feeding rate, aeration rate, circulating pressure, and underflow split ratio on the cyclonic separation efficiency [17]. Bai et al. developed a new process of utilizing air bubbles to enhance the separation efficiency of dispersed oil from water by hydrocyclones [18]. Fakhru'l-Razi et al. analyzed the technology development for oil and gas produced water treatment [19]. Karhu et al. studied the dissolved air flotation for treatment of oil-in-water emulsions prepared from synthetic oils by adding chemicals such as the cationic surfactant CTAB (cetyltrimethylammonium bromide), the coagulant PolyDADMAC (polydiallyldimethylammonium chloride) or Epi-DMA (epichlorohydrin-dimethylamine copolymer) directly into the saturator (PosiDAF) with two different concentrations, or by performing coagulation-flocculation followed by dissolved air flotation [20].

Both cyclonic and flotation are based on the theoretical of gravity separation. When oilfield produced water enters the hydro cyclones, oil droplets will move upward while the clean water will move downward by centrifugal force. However, the cyclones separation needs high inlet pressures and its retention time is short. Lighter and smaller oil droplets can be easily removed by gas flotation with the addition of chemical. Swirling air flotation technology combines both air flotation separation and cyclonic separation. The joint effect of the two kinds of separation, promoted the collision adsorption probability of micro bubbles and oil droplets, and effectively improved the separation efficient. Researchers have developed a cyclone air flotation integrated oil-water separation device to simplify the oilfield production process and improve the removal efficiency, but many of the works is conducted in the laboratory. Few cyclones air flotation oil-water separation devices are placed in oil fields. Therefore, a cylindrical oil-water separation apparatus that combines hydro cyclone and air-floating separation is designed to maximize the separation efficiency. Fluid path of flotation also contributes to greater oil-water separation.

The effect of the oilfield produced water treated by cyclones air flotation is unclear, and there is little reported in this field. The main purpose of this paper is to verify the feasibility of the apparatus through laboratory and field tests. In the laboratory test, the experiment was performed to obtain the optimum operating conditions that enhance the efficiency of separation. The effects of inlet flow, oil concentration, and aeration amount were also investigated. The field test is to verify the separation performance and operational stability of the cyclone air-floating integrated device during operation. Thus, a continuous stability experiment was carried out under experimental conditions.
The rest of this study is organized as follows. Section 3 describes the apparatus, materials, laboratory test process, and the analysis method. Section 4 gives the results and discussion, and finally, the conclusions are summarized in Section 5 .

\section{Materials and methods}

\subsection{Apparatus description}

An apparatus for separating oil and water was designed based on their different density and bubble-oil aggregate. The schematic of the experimental apparatus is shown in Fig. 1.

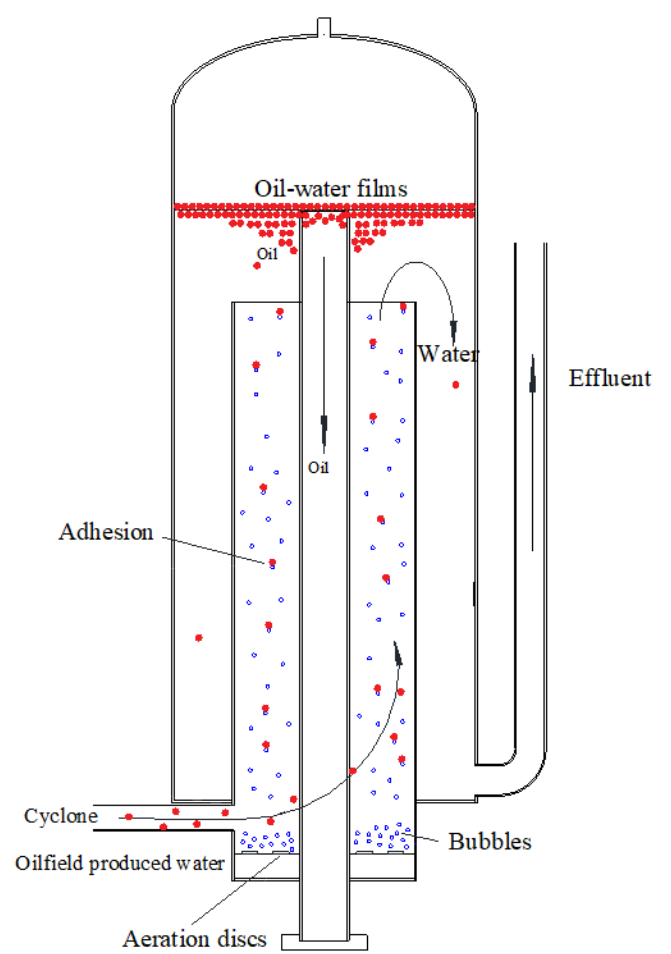

Fig. 1. Schematic of the cylindrical oil-water separation apparatus.

Different from other apparatus in previous studies, the designed apparatus has three concentric cylinders for functions as swirling, air-floating separation, and oil collection. The middle cylinder with $300 \mathrm{~mm}$ diameter is used to input oilfield-produced water including oil and water. The inner cylinder with a $75 \mathrm{~mm}$ diameter was used to collect the oil and the outer cylinder with a $500 \mathrm{~mm}$ diameter was used to collect the water. The height of the entire equipment is $1100 \mathrm{~mm}$, the center of the three cylinders is in a straight line and the middle cylinder is sealed. The height of the inner, middle and outside cylinder is $800 \mathrm{~mm}, 950$ and $1100 \mathrm{~mm}$, respectively. These heights are choose based on the numerical study. If the inner cylinder height is high, the velocity of the top liquid phase decreases under the action of the wall friction force, which is conducive to the stability of the oil-water separation interface. If the inner cylinder height is low, the produced water combined with the buddle cannot rise to the top of the interface, which is unfavorable for the separation oil and water. At the current height, the bubbles do not flow out of the outlet pipe and the oil droplets can rise to the oil-water interface. The main body of the experimental apparatus used mainly polymethyl methacrylate. The outlet of the apparatus is connected to a separate tank, which can be adjusted to a suitable height according to the flow. 
An aeration system with air as the carrier gas was used for air flotation to enhance the contact between oil droplet and gas bubble. The oil droplet suspended in the water and further attach to the gas bubble. The aeration system has four circular aeration discs that connect with the external air pump (the maximum $12 \mathrm{~L} / \mathrm{min}$ flow) in the bottom of the middle cylinder, which allows air to be bubbled up through the liquid in the cylinder. The four aeration discs with numerous $50 \mu \mathrm{m}$ micropores are connected by a four-way valve, which can adjust individually the intake air volume of each aeration disc. The bubbles are uniformly and continuously produced from the micropores. The top of the apparatus is open to the atmosphere through a hole.

In the laboratory test, the experimental system is mainly composed of a lifting pump, peristaltic pump, flow meter, static mixer, air pump, swirl air flotation cylinder, etc. The experiment process is shown in Fig. 2.

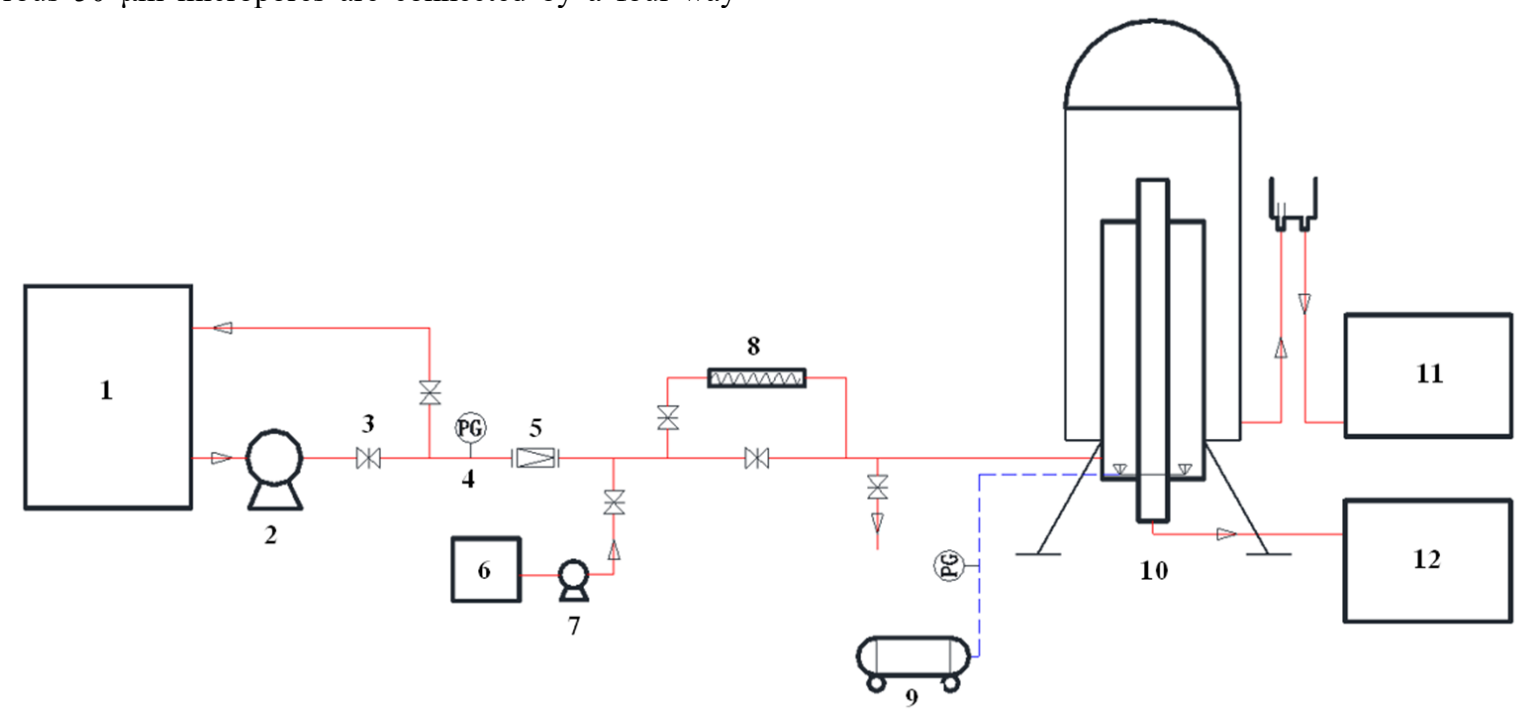

1-Clean water tank, 2-Lift pump, 3-Valve, 4-Float flowmeter, 5-Check valve, 6-Oil tank, 7-Peristaltic pump, 8-Static mixer, 9-Air pump, 10-Oil-water separation apparatus, 11-Collecting water tank, 12-Collecting oil tank.

Fig. 2. Diagram of removing oil by hydrocyclone air flotation system.

\subsection{Materials}

In the laboratory test, the oilfield produced water used in this experiment is a self-made mixture of vegetable oil and water. The density of vegetable oil is $915.2 \mathrm{~kg} / \mathrm{m}^{3}\left(20^{\circ} \mathrm{C}\right)$. All experiments were carried out at an indoor temperature of $20^{\circ} \mathrm{C}$.

In the field test, the oilfield produced water is from the outlet of the three-phase separator in Nanyang heavy-oil plant, China. During the test, the liquid pressure is 0.17 $\mathrm{MPa}$; the liquid temperature is $51-55^{\circ} \mathrm{C}$, with an average of $52.2{ }^{\circ} \mathrm{C}$; the water content of the oilfield produced water is $95.7-97.2 \%$, with an average of $96.4 \%$.

Tetrachloroethylene was purchased from Tianjin Kemiou Chemical Reagent Co., Ltd. Its melting point is $-22.2^{\circ} \mathrm{C}$, the boiling point is $121.2^{\circ} \mathrm{C}$, and the relative density is 1.63 .

\subsection{Laboratory test process}

At the beginning of the experiment, clean water was taken from the water tank using a lift pump (the maximum head is $16 \mathrm{~m}$ and the maximum flow is $12.5 \mathrm{~m}^{3} / \mathrm{h}$ ). At the same time, vegetable oil was fed into the apparatus according to the oil concentration required for the experiment using a peristaltic pump (the maximum rotation rate is $500 \mathrm{rpm}$ and the maximum flow is $1920 \mathrm{~mL} / \mathrm{min}$ ). Vegetable oil and water were mixed in the internal mixing unit at an appropriate proportion. In the movement process of the fluid, the mutually incompatible oil droplets and water were sheared, dispersed, and then mixed and emulsified. The flow ratio of the two branches can be controlled by adjusting the float flowmeter on the bypass pie and the oilfield produced water required in the laboratory is formed after confluence. The effects of inlet flow, oil concentration, and aeration amount on the oil removal rate were investigated.

\subsection{Analysis method}

The experiment uses the JKY-3A infrared oil detector (Jilin Science and Technology Research Institute, China) to measure oil concentration. The specific determination method is based on the Chinese water quality-Determination of petroleum, animal fats and vegetable oils- Infrared spectrophotometry (HJ637-2018). The reagent used in the extraction process was the infrared detection reagent tetrachloroethylene. The automatic extractor was used in the extraction process, following strictly the calculated residence time to ensure that the test results are more comparative. A correlation coefficient of 0.9999 was gained in the standard curve. The oil droplet size distribution was analyzed with a laser particle analyzer (BT2600, Dandong Bettersize instruments Ltd, China).

The oil removal rate is calculated as:

$\eta=\frac{C_{0}-C_{1}}{C_{0}} \times 100 \%$

where, $C_{0}$ is the oil concentration of the inlet stream, $\mathrm{mg} / \mathrm{L}$; $C_{1}$ is the oil concentration of the outlet stream, $\mathrm{mg} / \mathrm{L} ; H$ is the oil removal rate, $\%$.

\section{Results and discussion}

\subsection{Separation process description}

The oil field-produced water had similar separation behavior in the laboratory and field tests. It enters the flotation apparatus where the separation of the oil phase and water phase takes place. Under the action of the centrifugal force, the heavier phase moves to the wall of the cylinder and the lighter phase moves to the central position. The oil readily 


\section{Jianfei Liu, Hongbing Zhao, Huifang Li, Weilong Zhao, and Yongsheng Zhang/}

Journal of Engineering Science and Technology Review 13 (6) (2020) 61 - 67

attaches itself to the bubble because oil is hydrophobic [20]. The air bubbles will strike the oil droplets within the solution and the oil droplets collide with the bubbles and adhere. The oil field-produced water enters tangentially into the middle cylinder to enhance collision between oil droplets and air bubbles, which can improve flotation efficiency. Three-phase separation will take place in the film; thus, the liquid films play a significant role in the separation process.

In the early stage of operation, no film was formed and the oil concentration in the effluent was high. With the continuous generation of bubbles, the bubble-oil droplet adhering body can be floated together and continue to rise to the liquid/air interface. When the experimental conditions are stable, there is an equilibrium relationship between bubble-oil droplet and bubble in the oil-liquid film. The separation of oil droplets from oil produced water happens mainly in the oil-liquid film. With the increased number of bubbles rise, the equilibrium is disturbed, causing bubble-oil droplets to dissociate. There are three different behaviors in the films when it comes to a stable operation condition. Oil droplets will be skimmed off from the film and flow into the inner cylinder, the heavier water will move to outside cylinder under cyclonic force, and buddle will release into the atmosphere.

\subsection{Factors analysis of oil-water separation in laboratory}

\subsubsection{Inlet flow}

Inlet flow rate plays a vital role in the separation efficiency of the cyclone air flotation device. Thus, the inlet flow rate of $1.0,1.5,2,2.5$, and $3.0 \mathrm{~m}^{3} / \mathrm{h}$ are carried out with constant concentration at $1000 \mathrm{mg} / \mathrm{L}$ and the aeration amount at 0.6 $\mathrm{L} / \mathrm{min}$, and the results were shown in the Fig. 3. When the inlet flow rate is at $1.0,1.52 .0,2.5$, and $3.0 \mathrm{~m}^{3} / \mathrm{h}$, the oil content of the outlet varies from $89 \mathrm{mg} / \mathrm{L}$ to $441 \mathrm{mg} / \mathrm{L}$. The oil removal efficiency increased first and then decreased with the increased inlet flow rate. When the inlet flow rate is $1.5 \mathrm{~m}^{3} / \mathrm{h}$, the oil removal rate is highest at $91.1 \%$.

The experimental results show that the inlet flow has a great influence on the separation efficiency of oil and water. Lower flow rate means longer hydraulic retention time, which is benefit for the collision between oil droplets and air bubbles. However, the lower flow may not meet the requirement for treatment capacity and economic benefits. At the lower inlet flow $\left(1.0 \mathrm{~m}^{3} / \mathrm{h}\right)$, a large number of fine air bubbles and oil droplets can be observed at the top of the settling cylinder. When the inlet flow rate increased, a stable oil-water interface formed under the centrifugal force and the oil began to descend into the inner cylinder.

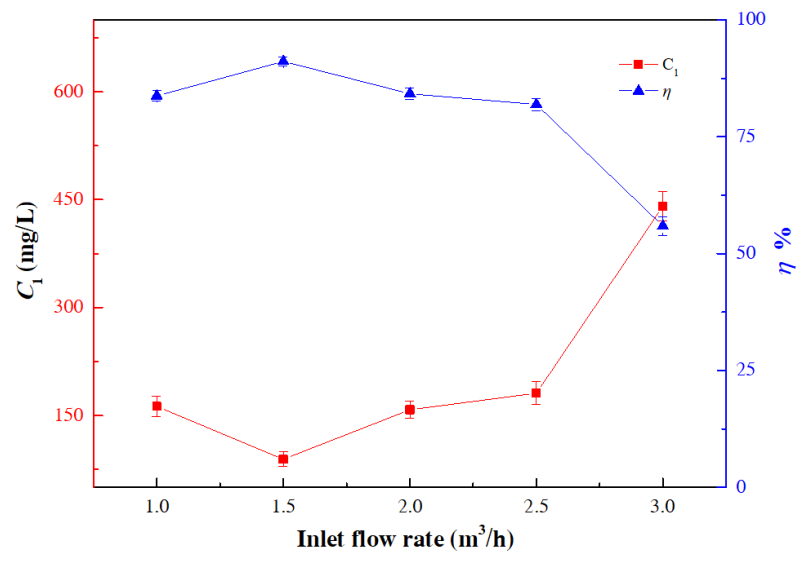

Fig. 3. Effect of inlet flow on oil removal efficiency.
In this case, the separation efficiency is higher and the effluent has a low oil content. When the inlet flow rate further increased, the disturbance at the top will be increased because of the high velocity and the oil-water interface cannot be stable. Under the larger shear force, the oil drops will be broken and emulsified [21], which will then be washed into the sedimentation tube again by water and discharged from the water outlet, thereby leading to the increase of oil content in the water outlet. Separation has a peak with the input flow rate, which is similar to the experiment results of Liu et al. [22].

\subsubsection{Oil concentration}

The inlet oil concentration reflects the adaptability of the cyclone air flotation device for the treatment of oilfield produced water with different concentrations. Tests involving inlet oil concentration at 500, 1000, 1500, 2000, and $3000 \mathrm{mg} / \mathrm{L}$ were carried out with constant inlet flow at 2 $\mathrm{m}^{3} / \mathrm{h}$, and aeration amount at $0.6 \mathrm{~L} / \mathrm{min}$. The results are shown in the Fig.4. When the oil concentration increased from 594 to $4162 \mathrm{mg} / \mathrm{L}$ and the oil concentration of the outlet varies from 89 to $441 \mathrm{mg} / \mathrm{L}$, with a constant inlet flow and aeration amount. The removal of oil efficiency increases first and then decreases with the increasing oil concentration.

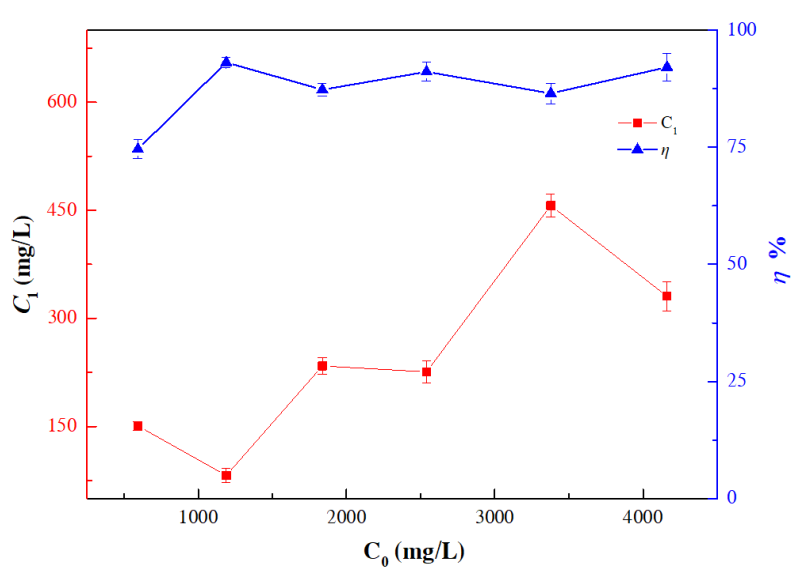

Fig. 4. Effect of oil concentration on oil removal efficiency.

For the apparatus, when the inlet flow rate is constant and the oil concentration of the oilfield produced water increases, the weight of oil increases at the same time. The increasing oil droplet weight increases the possibility of collision between the bubble and the oil droplet. During the collision process, the bubble-oil droplet adhering body can be floated together, so that a stable oil film with a certain thickness can quickly formed at the top of the apparatus, and the separation efficiency is improved [23].

However, as the oil concentration of the influent water increases to a certain extent, the oil film becomes too thick, which will block the top oil flow phase. Beyond the flotation ability of the air flotation, a large of oil droplets will appear near the water outlet, thereby resulting in the degreasing separation effect.The experimental result shows that when the influent oil concentration is $1189 \mathrm{mg} / \mathrm{L}$, the oil removal rate is at its highest value with $93.1 \%$. The results obtained are consistent with the trend of the data curve of Li et al. [24].

\subsubsection{Aeration amount}

Aeration amount is an important parameter of the cyclone air flotation device, which affects its final separation efficiency 
[25]. Tests with aeration amount at $0,0.3,0.6,0.9,1.2,1.5$, and $1.8 \mathrm{~L} / \mathrm{min}$ are carried out with constant inlet flow at 2 $\mathrm{m}^{3} / \mathrm{h}$ and inlet concentration at $1000 \mathrm{mg} / \mathrm{L}$. The results can be found in Fig.5. Oil removal efficiency increased first and then decreased with the increased aeration amount. When the aeration rate reaches $0.6 \mathrm{~L} / \mathrm{min}$, the oil removal rate is highest at $90.18 \%$.

The experimental results show when no air flotation is observed, part of the emulsified oil in the oil field-produced water cannot be separated and can only flow out with the water phase, leading to low separation efficiency. With the increase in aeration amount, the oil droplets combine with air bubbles, thereby increasing the buoyancy and cohesion of the oil droplets. Fig. 5 shows that when the aeration amount is relatively low, the number of micro bubbles formed is also low, resulting in a low oil removal rate.

When aeration amount is below $0.6 \mathrm{~L} / \mathrm{min}$, the oil removal efficiency increases with the increase in the aeration amount because there are enough bubbles and oil drop molecules to collide with oil [26]. However, as the aeration amount further increases to above $0.6 \mathrm{~L} / \mathrm{min}$, the oil removal rate decreases, which is because the oil-water mixture cannot form a stable oil-water interface when subjected to a large number of bubble impacts. When the stable interface is dispersed by bubbles, some oil is carried by the water to the settling tank, resulting in a decrease in separation efficiency. Furthermore, a high aeration amount means increasing energy consumption, which increases the operating cost of the experimental system. The results of this experiment are consistent with the conclusion trend of Qi et al. [27]. Therefore, in the actual production process, the aeration amount should be reasonably selected.

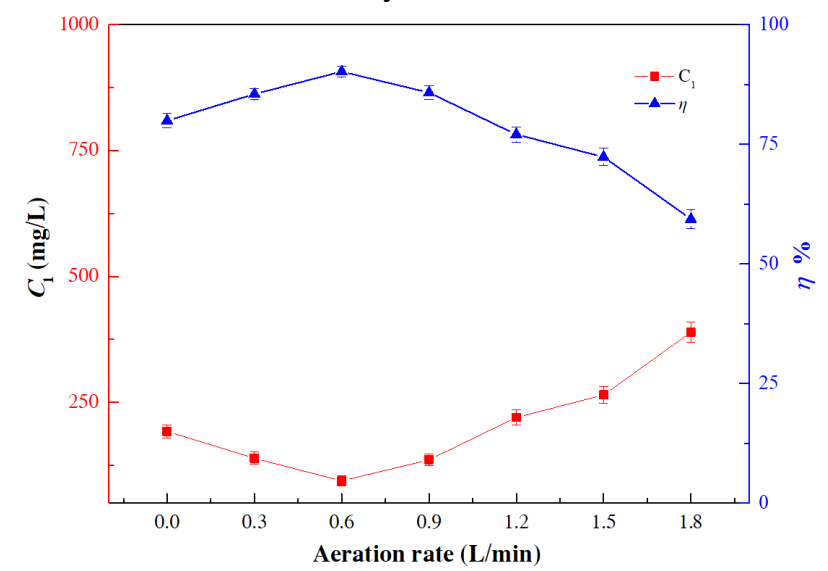

Fig. 5. Effect of aeration amount on oil removal efficiency.

\subsection{Field verification test}

The field verification test was conducted to verify the feasibility of the cyclonic flotation apparatus in oil fieldproduced water treatment. Photo of the field test was shown in Fig. 6. Although separation affection can reach $93.1 \%$ at the inlet flow rate of $2.0 \mathrm{~m}^{3} / \mathrm{h}$ and influent oil concentration is $1189 \mathrm{mg} / \mathrm{L}$ in the laboratory test, the field condition is relatively complicated. Different from the controllable conditions in a laboratory, concentrations and flow of oil vary significantly in a short period. High oil concentration and fluctuating flow are two obvious characteristics of oil field-produced water. Through some preliminary experiments, $1.35 \mathrm{~m}^{3} / \mathrm{h}$ is taken as the test flow to obtain a longer hydraulic retention time. Several oil removal rates from oilfield produced water cases are listed in Table. 1.

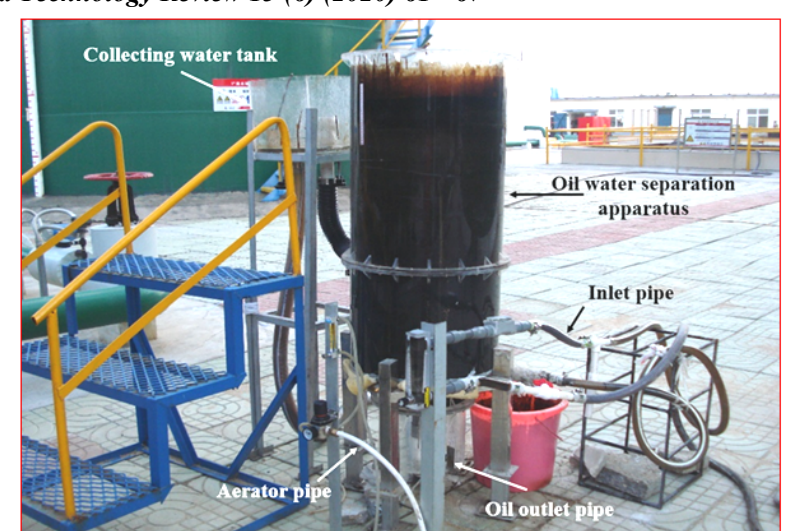

Fig. 6. Field test photo.

Table 1. Separation performance of field test.

\begin{tabular}{c|c|c|c|c}
\hline $\begin{array}{c}\text { Flow } \\
\text { rate } \\
\left(\mathbf{m}^{\mathbf{3}} \mathbf{h}\right)\end{array}$ & $\begin{array}{c}\text { Influent } \\
\text { concentration } \\
\mathbf{( m g / L )}\end{array}$ & $\begin{array}{c}\text { Effluent } \\
\text { concentration } \\
\mathbf{( m g / L )}\end{array}$ & $\begin{array}{c}\text { Aeration } \\
\text { amount } \\
(\mathbf{L} / \mathbf{m i n})\end{array}$ & $\begin{array}{c}\text { Removal } \\
\text { rate } \mathbf{( \% )}\end{array}$ \\
\hline 1.35 & 912.32 & 61.48 & 0.4 & 93.26 \\
1.35 & 1045.90 & 90.32 & 0.4 & 91.36 \\
1.35 & 1131.67 & 93.36 & 0.4 & 91.75 \\
1.35 & 1193.15 & 90.32 & 0.4 & 92.43 \\
1.35 & 1160.51 & 78.94 & 0.4 & 93.20 \\
1.35 & 1068.67 & 72.86 & 0.4 & 93.18 \\
\hline
\end{tabular}

The field test results show the cyclone air flotation test device has a good oil removal effect under the condition of a single-stage operation. The oil removal rate is generally above $90 \%$ when the influent concentration at 900-1200 $\mathrm{mg} / \mathrm{L}$, which indicates that the device has higher separation efficiency and good operational stability. The effluent concentration within the expected water quality index can guarantee long-term operation. It can be seen that the processing capacity of the equipment does not change greatly with the fluctuation of import concentration. Experimental data fully illustrate the high separation efficiency and stable water quality of the oil-water separation device. Radzuan verified that the oil removal efficiency is increasing linearly with the coagulant concentration by experiment [28]. The results shown that the lamp oil removal efficiencies were $31.7,45,50.2$, and $67.1 \%$ with Alum concentrations of $0,1.5,2.0$, and $2.5 \mathrm{~g} / \mathrm{L}$, respectively. High separation efficiency can be achieved without adding any chemical agents by the apparatus used in our work, which means many chemicals cost could be saved.

The particle size distribution of the influent and effluent oil produced water was analyzed to explore further the oil and water separation mechanism. The results are shown in Fig. 7 and Table. 2.

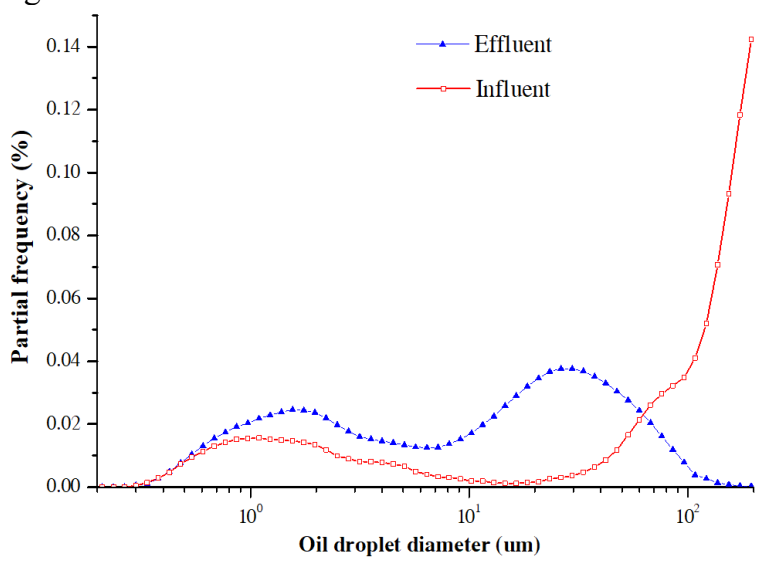

Fig. 7. Size distribution of the oil droplets in the influent and effluent. 
Table 2. The oilfield produced water concentration (mg/L).

\begin{tabular}{c|c|c|c}
\hline Name & Total oil & $\begin{array}{c}\text { Emulsified } \\
\text { oil }\end{array}$ & Free oil \\
\hline Influent & 1193.15 & 339.21 & 853.94 \\
Effluent & 90.32 & 56.59 & 33.73 \\
\hline
\end{tabular}

Oil phase which determined by oil droplet size within the water phase could be classed as free oil $(>150 \mu \mathrm{m})$, dispersed (20 to $150 \mu \mathrm{m})$, emulsified (5 to $20 \mu \mathrm{m})$, and soluble $(<5 \mu \mathrm{m})$ [29]. Free oil form mainly exist in the influent oil field-produced water and emulsified oil form mainly exist in the effluent oil field-produced water in this study. The removal effect is $88.7 \%$ and $97.5 \%$ for emulsified oil and free oil. The aeration discs have uniform micropores at $50 \mu \mathrm{m}$, bubbles are generated and discharged into the liquid, and the diffusion and dispersion of bubbles hardly affect the distribution of bubble size. Therefore, the bubbles should have similar diameter in the whole separation process. The result shows the bubbles have a high probability of collision and adhesion to the free oil for their high concentration. As result, most free oil droplets could rise to the liquid/air interface and flow into the inner cylinder, while the emulsified oil still exists for further demulsification treatment. The apparatus is suitable for the separation of free oil, and oilfield produced water mainly exists in the form of free oil.

The apparatus only has one inlet pipe, one water outlet pipe, one aerator pipe and one oil outlet pipe, which significantly simplifies the operation condition, and easy to implement automatic control. However, it should be noted that effluent oil concentration still does not meet the water quality standard of oilfield injecting waters in elastic reservoirs, it should enter the filter tank for further treatment. Thus, the cyclonic flotation apparatus can be used as a pretreatment unit for the next treatment processes.

\section{Conclusion}

Combines with both air flotation separation and cyclonic separation, an integrated oil-water separation apparatus was developed to determine the separation effectiveness of oil and water from oilfield produced water without the addition of chemical agents. To validate the separation performance of separation apparatus, lab-scale and field tests for treating oilfield produced water were carried out. The main conclusions are as follows:

(1) With simple operation and compact design, the cyclonic flotation apparatus has high separation efficiency and good operational stability without the addition of chemical agents. The effect of the separation apparatus based on air flotation and cyclonic separation is verified.

(2) The optimum operating conditions of the inlet flow, oil concentration and aeration amount are obtained and the separation effective is generally above $90 \%$ in the lab and field test. Both emulsified oil and free oil have better removal effect by particle size analysis. Compared with other flotation apparatus, the removal rate is higher for its unique design and can be used as a pretreatment unit.

The integrated oil-water separation apparatus was developed to determine the separation effectiveness of oil and water from oilfield produced water in this study. With the development of engineering practice, this equipment needs to be further optimized and improved to face the new complex problems.

\section{Acknowledgements}

This study was supported by Key Scientific Research Project of Higher Education Department of Henan province (21B610006), Henan oilfield Engineering Consulting Co., Ltd, and Nanyang heavy-oil plant, China.

This is an Open Access article distributed under the terms of the Creative Commons Attribution License

\section{References}

1. Blecich, P., Wolf, I., Bonefačić, I., "Numerical investigation of heat and mass transfer inside a wet cooling tower". Technical Journal, 12(3), 2018, pp. 131-138.

2. Gutierrez, J. C., Ochoa, G. V., Forero, J. D., "Parametric analysis CFD of the hydraulic performance of a centrifugal pump with applications to the dredging industry". Journal of Engineering Science and Technology Review, 13(3), 2020, pp. 8-14.

3. Yan, H., Yu, C., Chai, L. P., Li, Y. Q., Vnenkovskaia, V., Chen, H., "Design and investigation of the hydraulic performance of bionic hydrofoil based on the geometric features of sturgeons". Dyna, 94(3), 2019, pp. 278-285.

4. Zivic, M., Galovic, A., Avsec, J., Barac, A., "Application of gas condensing boilers in domestic heating". Tehnicki VjesnikTechnical Gazette, 26(3), 2019, pp. 681-685.

5. Hosseini, S. E., Akhavan, A. N., Bahrami, M., "Designing an integrated model of oil and gas management with a SWOT approach: the case of NIOC". Technical Journal, 14(4), 2020, pp. 440-445.

6. Al-Obaidi, A. R., Mohammed, A. A., "Numerical investigations of transient flow characteristic in axial flow pump and pressure fluctuation analysis based on the CFD technique". Journal of Engineering Science and Technology Review, 12(6), 2019, pp. 7079

7. Zhang, B., Dou, Y. Y., Hong, Q., Ji, H. H., "Numerical investigation of flow and heat transfer characteristics in plate with multiple incline stage holes". Tehnicki Vjesnik-Technical Gazette, 26(2), 2019, pp. 471-477.

8. Salazar, M. G., Jimenez, R. Z., Reyes, A. H., "Moisture removal assessment using desiccant liquids with a bubble-air generator". Dyna, 93(3), 2018, pp. 286-292.

9. Saththasivam, J., Loganathan, K., Sarp, S., "An overview of oilwater separation using gas flotation systems". Chemosphere, 144, 2016, pp. 671-680.

10. Lim, M. W., Lau, E. V., Poh, P. E., "Micro-macrobubbles interactions and its application in flotation technology for the recovery of high density oil from contaminated sands". Journal of Petroleum Science and Engineering, 161, 2018, pp. 29-37.

11. Huang, L., Deng, S. S., Guan, J. F., Chen, M., Hua, W. X. "Development of a novel high-efficiency dynamic hydrocyclone for oil-water separation". Chemical Engineering Research and Design, 130, 2018, pp. 266-273.

12. Etchepare, R., Oliveira, H., Azevedo, A., Rubio, J., "Separation of emulsified crude oil in saline water by dissolved air flotation with micro and nanobubbles". Separation and Purification Technology, 186, 2017, pp. 326-332

13. Wang X., "Application of vortex floating technology on the FPSO of offshore oilfield", Oil-Gasfield Surface Engineering, 36(6), 2017, pp.54-56.

14. Yan, S. L., Yang, X. Y., Bai, Z.S., Xu, X., Wang, H. L., "Drop attachment behavior of oil droplet-gas bubble interactions during flotation". Chemical Engineering Science, 223, 2020, pp. 115740.

15. Ammar, S. H., Akbar, A. S., "Oilfield produced water treatment in internal-loop airlift reactor using electrocoagulation/flotation technique". Chinese Journal of Chemical Engineering, 26(4), 2018, pp. 879-885.

16. Gebreyohannes, A. Y., Mazzei, R., Giorno, L., "Trends and current 
Jianfei Liu, Hongbing Zhao, Huifang Li, Weilong Zhao, and Yongsheng Zhang/

Journal of Engineering Science and Technology Review 13 (6) (2020) 61 - 67

practices of olive mill wastewater treatment: Application of integrated membrane process and its future perspective". Separation and Purification Technology, 162, 2016, pp. 45-60.

17. Liu, J. T., Xu, H. X., Li, X. B., "Cyclonic separation process intensification oil removal based on microbubble flotation". International Journal of Mining Science and Technology, 23(3), 2013, pp. 415-422.

18. Bai, Z. S., Wang, H. L., Tu, S. T., "Oil-water separation using hydrocyclones enhanced by air bubbles". Chemical Engineering Research and Design, 89(1), 2011, pp. 55-59.

19. Fakhru'l-Razi A., Pendashteh, A., Abdullah, L. C., Biak, D. R. A., Madaeni, S. S., Abidin, Z. Z., "Review of technologies for oil and gas produced water treatment". Journal of Hazardous Materials, 170(2), 2009, pp. 530-551.

20. Karhu, M., Leiviskä, T., Tanskanen, J., "Enhanced DAF in breaking up oil-in-water emulsions". Separation and Purification Technology, 122, 2014, pp. 231-241.

21. Zhao, L. X., Jiang, M. H., Li, F., "Experimental study on the separation performance of air-injected de-oil hydrocyclones". Chemical Engineering Research and Design, 88(5-6), 2010, pp. $772-778$.

22. Liu, H. F., Xu, J., Zhang, J. Y., Sun, H., Zhang, J. Q., Wu, Y., "Oil/Water separation in a liquid-liquid cylindrical cyclone". Journal of Hydrodynamics, 24(1), 2012, pp. 116-123.

23. Grattoni, C., Moosai, R., Dawe, R. A., "Photographicobservations showing spreading and non-spreading of oil on gas bubbles of relevance to gas flotation for oily wastewatercleanup". Colloids and
Surfaces A: Physicochemical andEngineering Aspects, 214(1), 2003, pp. 151-155.

24. Li, X. B., Xu, H. X., Liu, J. T., Zhang, J., Li, J., Gui, Z. L., "Cyclonic state micro-bubble flotation column in oil-in-water emulsion separation". Separation and Purification Technology, 165, 2016, pp. 101-106.

25. Painmanakul, P., Sastaravet, P., Lersjintanakarn, S., Khaodhiar, S., "Effect of bubble hydrodynamic and chemical dosage on treatment of oily wastewater by Induced Air Flotation (IAF) process". Chemical Engineering Research and Design, 88(5-6), 2010, pp. 693-702.

26. Ran, J. C., Liu, J. T., Zhang, C. J., Wang, D. Y., Li, X. B., "Experimental investigation and modeling of flotation column for treatment of oily wastewater". International Journal of Mining Science and Technology, 23(5), 2013, pp. 665-668.

27. Qi, W. K., Yu, Z. C., Liu, Y. Y., Li, Y. Y., "Removal of emulsion oil from oilfield ASP wastewater by internal circulation flotation and kinetic models". Chemical Engineering Science, 91, 2013, pp. 122-129.

28. Radzuan, M. R. A., Belope, A. B., Thorpe, R. B., "Removal of fine oil droplets from oil-in-water mixtures by dissolved air flotation". Chemical Engineering Research and Design, 115, 2016, pp. 115133.

29. Edzwald J. K., "Principles and applications of dissolved air flotation". Water Science and Technology, 31(3-4), 1995, pp. 1-23. 